Instrumental Achievements

\title{
Crystal Structure of Bis(diethyldithiocarbamato)palladium(II) Benzene Solvate, $\left[\mathrm{Pd}\left(\mathrm{Et}_{2} \mathrm{dtc}\right)_{2}\right] \cdot\left(\mathrm{C}_{6} \mathrm{H}_{6}\right)$
}

\author{
Masahiko MaEkawa*†, Megumu Munakata**†, Takayoshi KuRodA-SowA ${ }^{* *}$ \\ and Masanori MotoKaWA** \\ *Research Institute for Science and Technology, Kinki University, \\ Kowakae, Higashi-Osaka 577, Japan \\ ** Department of Chemistry, Kinki University, Kowakae, Higashi-Osaka 577, Japan
}

Since palladium(II) belongs to a class $b$ or a soft metal ion, it forms relatively stable complexes with sulfur- and phosphorous-containing ligands. ${ }^{1}$ Many Pd(II) complexes with dithiolate ligands have already been prepared and characterized. ${ }^{1}$ Although Pd(II) complexes with dithiocarbamate have been prepared and systematically characterized based on the IR and electronic spectra ${ }^{2}$, the crystal structure has not been reported. In this study we have characterized bis(diethyldithiocarbamato)palladium(II) crystallographically.

Yellow single crystals of $\left[\mathrm{Pd}\left(\mathrm{Et}_{2} \mathrm{dtc}\right)_{2}\right] \cdot \mathrm{C}_{6} \mathrm{H}_{6}\left(\mathrm{Et}_{2} \mathrm{dtc}=\right.$ diethyldithiocarbamate) (1) were obtained from a mixture solution of $\left[\mathrm{Pd}(\mathrm{PhCN})_{2} \mathrm{Cl}_{2}\right]\left(46 \mathrm{mg}, 1.2 \times 10^{-4} \mathrm{~mol}\right)$, sodium diethylthiocarbamate $\left(28 \mathrm{mg}, 1.2 \times 10^{-4} \mathrm{~mol}\right)$, triphenylphosphine ( $\left.32 \mathrm{mg}, 1.2 \times 10^{-4} \mathrm{~mol}\right), \mathrm{NaBH}_{4}(27 \mathrm{mg}$, $\left.7.2 \times 10^{-4} \mathrm{~mol}\right)$ and trichloroethylene $\left(1.1 \mathrm{ml}, 1.2 \times 10^{-2}\right.$ $\mathrm{mol})$ in benzene/methanol $(16 \mathrm{ml}, \mathrm{v} / \mathrm{v}=3 / 5)$ after two weeks. Data collection was performed on a Rigaku AFC-5R diffractometer under the conditions given in Table 1. The structure was solved by a direct method

Table 1 Crystal and experimental data

Formula: $\mathrm{PdS}_{4} \mathrm{~N}_{2} \mathrm{C}_{16} \mathrm{H}_{26}$

Formula weight: 481.04

Crystal system: triclinic

Space group: $P \overline{\mathbf{l}} \quad Z=1$

$a=8.883(1) \AA$

$b=9.017(2) \AA$

$c=7.446(1) \AA$

$\alpha=111.88(1)^{\circ}$

$\beta=110.45(1)^{\circ}$

$\gamma=86.66(2)^{\circ}$

$V=516.8(4) \AA^{3}$

$D_{\text {calc }}=1.545 \mathrm{~g} / \mathrm{cm}^{3}$

$R=0.026, R w^{\prime}=0.038$

No. of reflections used $=2198(I>3 \sigma(I))$

Measurement: Rigaku AFC-5R

Program system: TEXSAN

Structure determination: direct method (MITHRIL)

Refinement: full-matrix least-square

† To whom correspondence should be addressed.
(MITHRIL) $^{3}$ and an empirical, spherical, absorption correction was performed using a program called DIFABS $^{4}$ after an isotropic refinement for all of the nonhydrogen atoms. The scattering factors and anomalous dispersion corrections for non-hydrogen atoms were taken from ref. 5. A refinement of the non-hydrogen atomic positional and thermal anisotropic parameters was performed by a full-matrix least-squares calculation. The positions of the hydrogen atoms were obtained from a difference Fourier synthesis. All of the calculations were performed using a TEXSAN ${ }^{6}$ crystallographic software package. The atomic positional parameters are given in Table 2.

The molecular structure of 1 is shown in Fig. 1, together with the solvated benzene molecule. Selected bond distances and angles are listed in Table 3. Complex 1 has symmetry center on a $\mathbf{P d}(1)$ atom. The $P d$ atom is coordinated by four $\mathrm{S}$ atoms of two $\mathrm{Et}_{2} \mathrm{dtc}$ ligands in a square-planar geometry. The average $\mathbf{P d}-\mathrm{S}$ distance of $2.3277(7) \AA$ is within those $(2.31-2.35 \AA$ ) of the Pd(II) complexes with the dithiolate ligand. ${ }^{7}$ The $\mathrm{S}(1)-\mathrm{Pd}(1)-$ $\mathrm{S}(2)$ angle of $75.09(2)^{\circ}$ is also close to those $\left(73.6-75.4^{\circ}\right)$ of the Pd(II) complexes with the dithiolate ligand. ${ }^{7}$ The

Table 2 Final atomic coordinates and equivalent isotropic thermal parameters $B_{\text {eq }}\left(\AA^{2}\right)$ of non-hydrogen atoms

\begin{tabular}{lllll}
\hline Atom & \multicolumn{1}{c}{$x$} & \multicolumn{1}{c}{$y$} & \multicolumn{1}{c}{$z$} & \multicolumn{1}{c}{$B_{\text {eq }}$} \\
\hline $\mathrm{Pd}(1)$ & 1.0000 & 0 & 1.0000 & $3.495(6)$ \\
$\mathrm{S}(1)$ & $0.96033(7)$ & $0.18423(7)$ & $0.8404(1)$ & $4.47(2)$ \\
$\mathrm{S}(2)$ & $1.20899(7)$ & $-0.02717(7)$ & $0.8718(1)$ & $4.52(2)$ \\
$\mathrm{N}(1)$ & $1.1903(2)$ & $0.1784(2)$ & $0.6806(3)$ & $4.15(5)$ \\
$\mathrm{C}(1)$ & $1.1291(2)$ & $0.1203(3)$ & $0.7812(3)$ & $3.79(6)$ \\
$\mathrm{C}(2)$ & $1.3356(3)$ & $0.1165(3)$ & $0.6348(4)$ & $5.18(8)$ \\
$\mathrm{C}(3)$ & $1.4880(3)$ & $0.2127(5)$ & $0.7956(5)$ & $6.9(1)$ \\
$\mathrm{C}(4)$ & $1.1153(3)$ & $0.3070(3)$ & $0.6116(4)$ & $4.94(8)$ \\
$\mathrm{C}(5)$ & $1.1694(5)$ & $0.4716(4)$ & $0.7734(5)$ & $6.9(1)$ \\
$\mathrm{C}(6)$ & $1.3577(5)$ & $0.4374(6)$ & $0.3439(5)$ & $8.4(1)$ \\
$\mathrm{C}(7)$ & $1.4845(6)$ & $0.3476(4)$ & $0.3677(5)$ & $8.1(1)$ \\
$\mathrm{C}(8)$ & $1.6267(4)$ & $0.4089(5)$ & $0.5227(7)$ & $8.5(1)$ \\
\hline
\end{tabular}

$B_{\mathrm{eq}}=(4 / 3) \Sigma_{i} \Sigma_{j} \beta_{i j}\left(a_{i} \cdot a_{j}\right)$. 


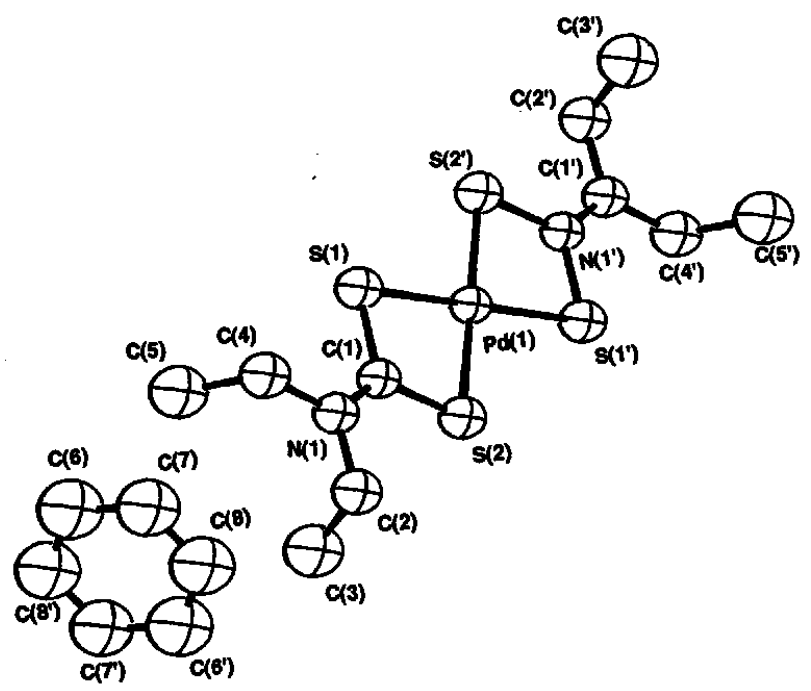

Fig. 1 Molecular structure of $\left[\mathrm{Pd}\left(\mathrm{Et}_{2} \mathrm{dtc}\right)_{2}\right] \cdot\left(\mathrm{C}_{6} \mathrm{H}_{6}\right)(\mathbf{1})$.

Table 3 Selected bond distances $(\AA)$ and bond angles $\left({ }^{\circ}\right)$

\begin{tabular}{llll}
\hline $\mathrm{Pd}(1)-\mathrm{S}(1)$ & $2.3253(7)$ & $\mathrm{Pd}(1)-\mathrm{S}(2)$ & $2.3301(7)$ \\
$\mathrm{S}(1)-\mathrm{C}(1)$ & $1.716(2)$ & $\mathrm{S}(2)-\mathrm{C}(1)$ & $1.718(2)$ \\
$\mathrm{N}(1)-\mathrm{C}(1)$ & $1.319(3)$ & $\mathrm{N}(1)-\mathrm{C}(2)$ & $1.476(3)$ \\
$\mathrm{N}(1)-\mathrm{C}(4)$ & $1.472(3)$ & & \\
$\mathrm{S}(1)-\mathrm{Pd}(1)-\mathrm{S}(2)$ & $75.09(2)$ & $\mathrm{S}(1)-\mathrm{Pd}(1)-\mathrm{S}\left(2^{\prime}\right)$ & $104.91(2)$ \\
$\mathrm{Pd}(1)-\mathrm{S}(1)-\mathrm{C}(1)$ & $86.86(8)$ & $\mathrm{Pd}(1)-\mathrm{S}(2)-\mathrm{C}(1)$ & $86.66(8)$ \\
\hline
\end{tabular}

intermolecular plane distance among the $\mathrm{PdS}_{4}$ planes is far apart, and no specific intermolecular stacking was found. The close Pd...S distance between the Pd atom and the $\mathrm{S}$ atom of the neighboring $\mathrm{PdS}_{4}$ plane is also $5.981 \AA$, not indicative of the intermolecular Pd $\mathrm{PS}$ interaction $(\mathrm{Pd}-\mathrm{S}=3.32 \AA$ ) found in the bis(dithiobenzoato)palladium(II) complex. ${ }^{7}$ Four ethyl groups of the coordinating $\mathrm{Et}_{2} \mathrm{dtc}$ are perpendicular to the $\mathbf{P d S}_{\mathbf{4}}$ plane. Interestingly, two ethyl groups of each $\mathrm{Et}_{2} \mathrm{dtc}$ ligand are directed to the same orientation. Two of the four ethyl groups are directed to the upper side of the $\mathrm{PdS}_{4}$ plane; the other two ethyl groups are directed to the lower side of the $\mathrm{PdS}_{4}$ plane. This conformation is different from that of free $\mathrm{Et}_{2} \mathrm{dtc}^{8}$, because two ethyl groups of free $\mathrm{Et}_{2} \mathrm{dtc}$ are directed to the opposite orientation from each other. The solvated benzene molecule inculdes almost perpendicular to the $\mathrm{PdS}_{4}$ planar, although an intermolecular $\pi-\pi$ interaction does not exist among the solvated benzene molecules.

We thank Mr. Isamu Furuchi and Mr. Koji Hachiya for their assistance with the X-ray measurement. This work was partially supported by Grant-in-Aid for Science Research (Nos. 06740517,06269209 and 05453131) from the Ministry of Education, Science and Culture.

\section{References}

1. A. T. Hutton, "Comprehensive Coordination Chemistry", ed. G. Wilkinson, Vol. 5, Chap. 51.8, pp. 1131-1155, Pergamon, New York, 1987.

2. C. G. Sceney and R. J. Magee, Inorg. Nucl. Chem. Lett., 10, 323 (1974) and reference therein.

3. "MITHRIL", J. Gilmore, J. Appl. Crystallogr., 17, 42, Univ. of Glasgow, Scotland, 1984.

4. "DIFABS", N. Walker and D. Stewart, Acta Crystallogr., Sect A, 39, 158 (1983).

5. "International Tables for X-ray Crystallography", Vol. IV, The Kynoch Press, Birmingham, 1974.

6. "TEXSAN", TEXRAY Structure Analysis Package, Molecular Structure Corporation, The Woodlands, Tx, USA, 1985.

7. Table 2 in ref. 1.

8. M. Colapietro, A. Domenicano and A. Vaciago, J. Chem. Soc., Chem. Commun., 572 (1968).

(Received August 29, 1994) (Accepted October 3, 1994) 